\title{
Using Models for the Optimization of Hydrologic Monitoring
}

\section{Introduction}

Hydrologists are often asked what kind of monitoring network can most effectively support science-based waterresources management decisions. Currently (2011), hydrologic monitoring locations often are selected by addressing observation gaps in the existing network or non-science issues such as site access. A model might then be calibrated to available data and applied to a prediction of interest (regardless of how well-suited that model is for the prediction). However, modeling tools are available that can inform which locations and types of data provide the most "bang for the buck" for a specified prediction. Put another way, the hydrologist can determine which observation data most reduce the model uncertainty around a specified prediction.

An advantage of such an approach is the maximization of limited monitoring resources because it focuses on the difference in prediction uncertainty with or without additional collection of field data. Data worth can be calculated either through the addition of new data or subtraction of existing information by reducing monitoring efforts (Beven, 1993). The latter generally is not widely requested as there is explicit recognition that the worth calculated is fundamentally dependent on the prediction specified. If a water manager needs a new prediction, the benefits of reducing the scope of a monitoring effort, based on an old prediction, may be erased by the loss of information important for the new prediction.

This fact sheet focuses on the worth or value of new data collection by quantifying the reduction in prediction uncertainty achieved be adding a monitoring observation. This calculation of worth can be performed for multiple potential locations (and types) of observations, which then can be ranked for their effectiveness for reducing uncertainty around the specified prediction. This is implemented using a Bayesian approach with the PREDUNC utility in the parameter estimation software suite PEST (Doherty, 2010).

\section{The Role of "Potential Observations"}

Evaluation of the worth of additional data does not require that we actually know the observed values at the proposed monitoring locations. Rather, it requires only that we know the proposed observations' sensitivity to parameter perturbation in the model. Such information is easily calculated using a parameter-estimation approach and is encapsulated in the "Jacobian matrix" (a matrix that reports the response of each observation to a perturbation of each parameter).

Moreover, the Jacobian matrix can be calculated at any stage of the calibration process; thus, this approach is applicable to precalibration or other early stages of an investigation.
The techniques briefly described earlier are described in detail in a U.S. Geological Survey Scientific Investigations Report available on the Internet (Fienen and others, 2010; http://pubs.usgs.gov/sir/2010/5159/). This fact sheet presents a synopsis of the techniques as applied to a synthetic model based on a model constructed using properties from the Lake Michigan Basin (Hoard, 2010).

\section{A Highly Parameterized Approach to Achieving Model Parsimony}

An important aspect of designing a model is deciding the structure and number of parameters used to represent a natural world of unknowable complexity (Hunt and others, 2007; Hunt and Welter, 2010). The level of parameterization can have important ramifications for the ability of the model to take full advantage of the information encapsulated in the field data. Perhaps less intuitively, parameterization also can affect the ability of the model to assess effects on predictions which, in turn, affects the ability of the model to determine the worth of future data collection (Fienen and others, 2010). A highly parameterized model does not necessarily mean that the model will be highly heterogeneous (or have unrealistic distributions of properties or suffer from instability and nonuniqueness; e.g., Fienen and others, 2009). This is because mathematical methods (regularized inversion) are available to constrain insensitive and correlated parameters with subjective information - a modeler's soft-knowledge - and provide the ability to solve the problem with a reduced set of linear combinations of model inputs unconditionally informed by the observations (Hunt and others, 2007; Doherty and Hunt, 2010a). The mathematical tools collapse the highly parameterized problem to something "as simple as possible," and high numbers of parameters help ensure that the twin requirement of parsimony - "but not simpler"-also is met (Doherty and Hunt, 2010b).

\section{Using a Model to Optimize Hydrologic Monitoring}

To demonstrate the utility of the methods described herein, a synthetic model, based on a local inset model constructed using properties from the Lake Michigan Basin (Hoard, 2010), is used to determine the optimal future data-collection locations needed to optimize network design. The specified prediction of interest is the amount of groundwater-level change in an area of interest; for example, an area with an endangered plant species. The ultimate goal of the monitoring is to assess the effect of a new high-capacity pumping well (500 gallons per minute $(\mathrm{gal} / \mathrm{min}))$ in this area, which also is near a headwater stream. 
The original local model inset was constructed to evaluate the effects of groundwater pumping on groundwater/surfacewater interaction (Hoard, 2010) and is described briefly herein. The model uses a telescopic mesh-refinement approach where a local model was constructed (cell size $=21.8$ meters $(\mathrm{m})$ ) within an intermediate model (cell size $=152.4 \mathrm{~m}$ ), which was, in turn, inset within a regional model (cell size ranging from $1,524 \mathrm{~m}$ to more than 21,000 m) of the Lake Michigan Basin (Feinstein and others, 2010). The objective of the local-scale modeling involved the water-balance question of effects of pumping on the flow to a headwater stream. Figure 1 shows the features and locations of the regional, intermediate, and local models. The model contains six layers; the two shallowest layers are of principal interest in this investigation. Recharge and fixed-head lateral boundaries, simulated with the $\mathrm{RCH}$ and BAS packages within MODFLOW-2005, Version 1.6 (Harbaugh, 2005), combine with surface-water features modeled through the streamflow routing (SFR) package to represent water inflows and outflows. Further details about the model features and implementation are discussed in Hoard (2010).
To demonstrate the effect of parameterization on dataworth analyses, three parameterization resolutions are considered (fig. 2$)^{1}$ : (1) a hydraulic conductivity $(K)$ layer-multiplier ("1 Zone") approach in which a single multiplier is applied to all horizontal $\left(\mathrm{K}_{\mathrm{h}}\right)$ and vertical $\left(\mathrm{K}_{\mathrm{v}}\right)$ hydraulic-conductivity values in each of the 6 layers resulting in a 12-parameter model; (2) a 25-zone version of the model ("25 Zones") in which $25 \mathrm{~K}_{\mathrm{h}}$ and $25 \mathrm{~K}_{\mathrm{v}}$ zones are specified in each of the 6 layers resulting in a 300-parameter model; and (3) a pilot-point ("400 Pilot Points") approach in which a 20 by 20 grid of pilot points (Doherty, 2003) represents both $\mathrm{K}_{\mathrm{h}}$ and $\mathrm{K}_{\mathrm{v}}$ in each of the 6 layers resulting in a 4,800-parameter model. In the "400 Pilot Points" approach, the estimated parameter values are interpolated to the model grid in areas between the pilot points using Kriging.

It is important to note that only the parameter flexibility (specified for the data-worth analysis) was being varied in the three cases described above; the actual hydraulic conductivity values input into the model were exactly the same in all three cases and were equal to those inherited from the calibrated regional model.

${ }^{1}$ The terminology used here to describe the three parameterizations is modified for clarity from the more extensive analysis of Fienen and others (2010).

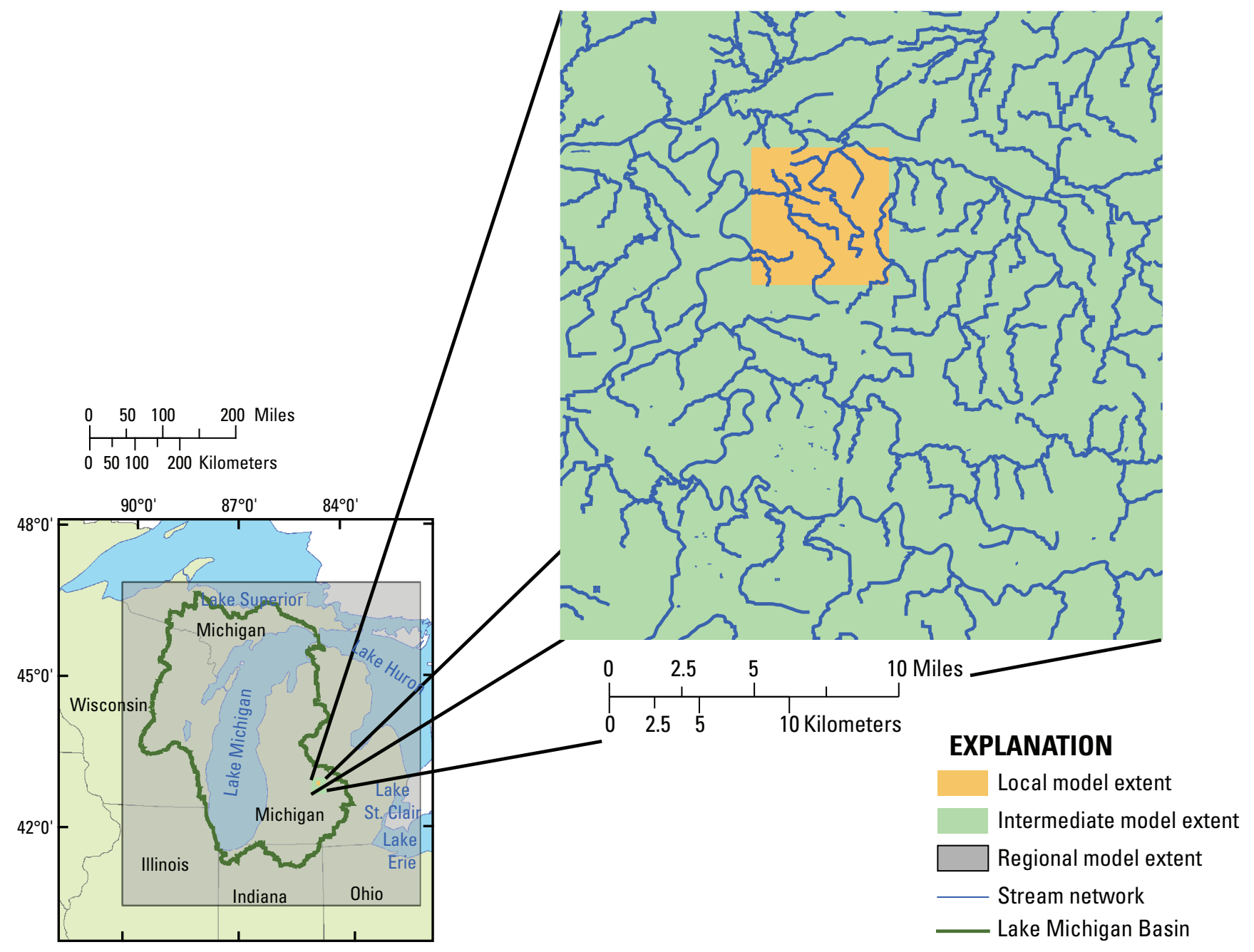

Figure 1. The location and features of the regional, intermediate, and local models (modified from Hoard, 2010). 

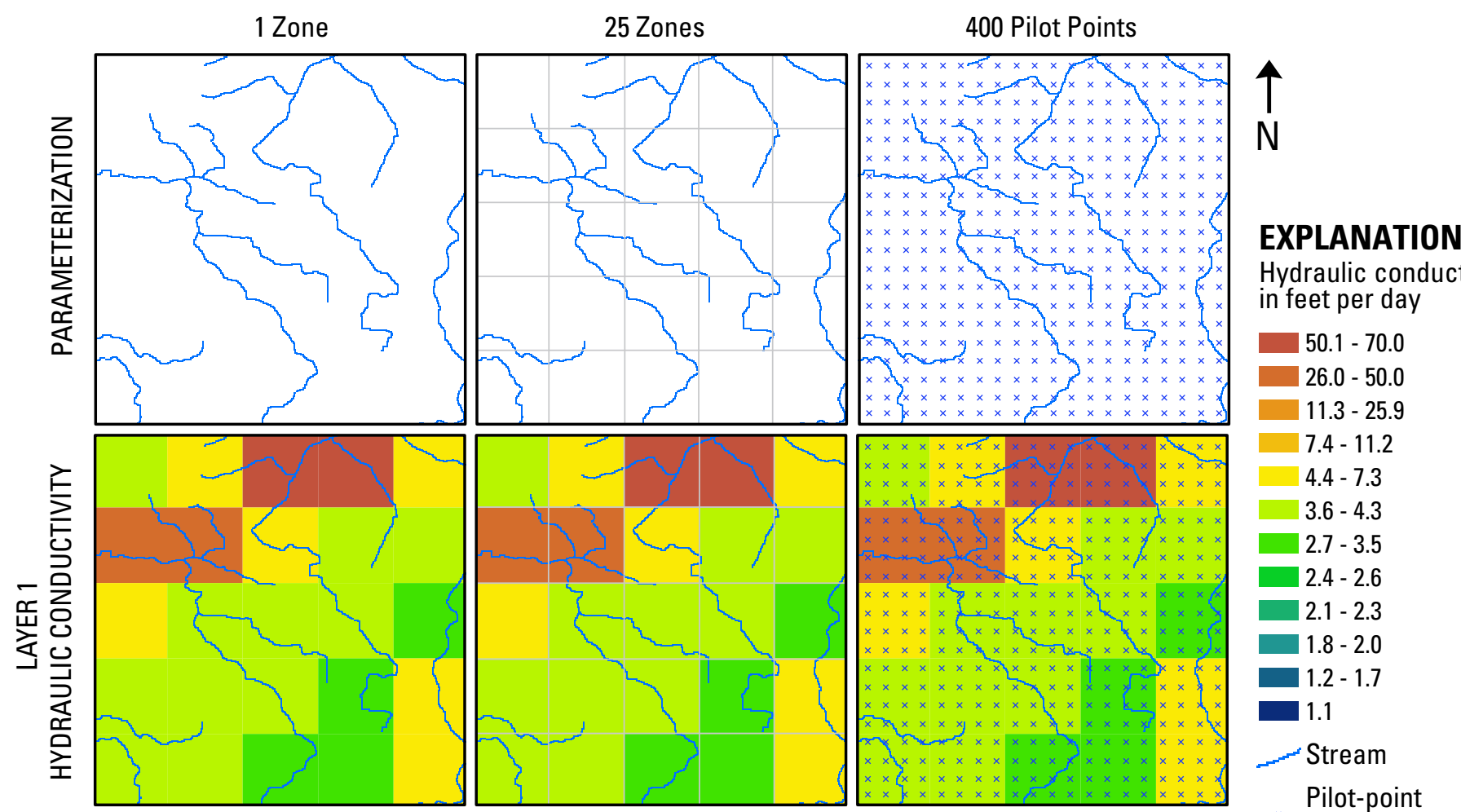

Hydraulic conductivity, in feet per day
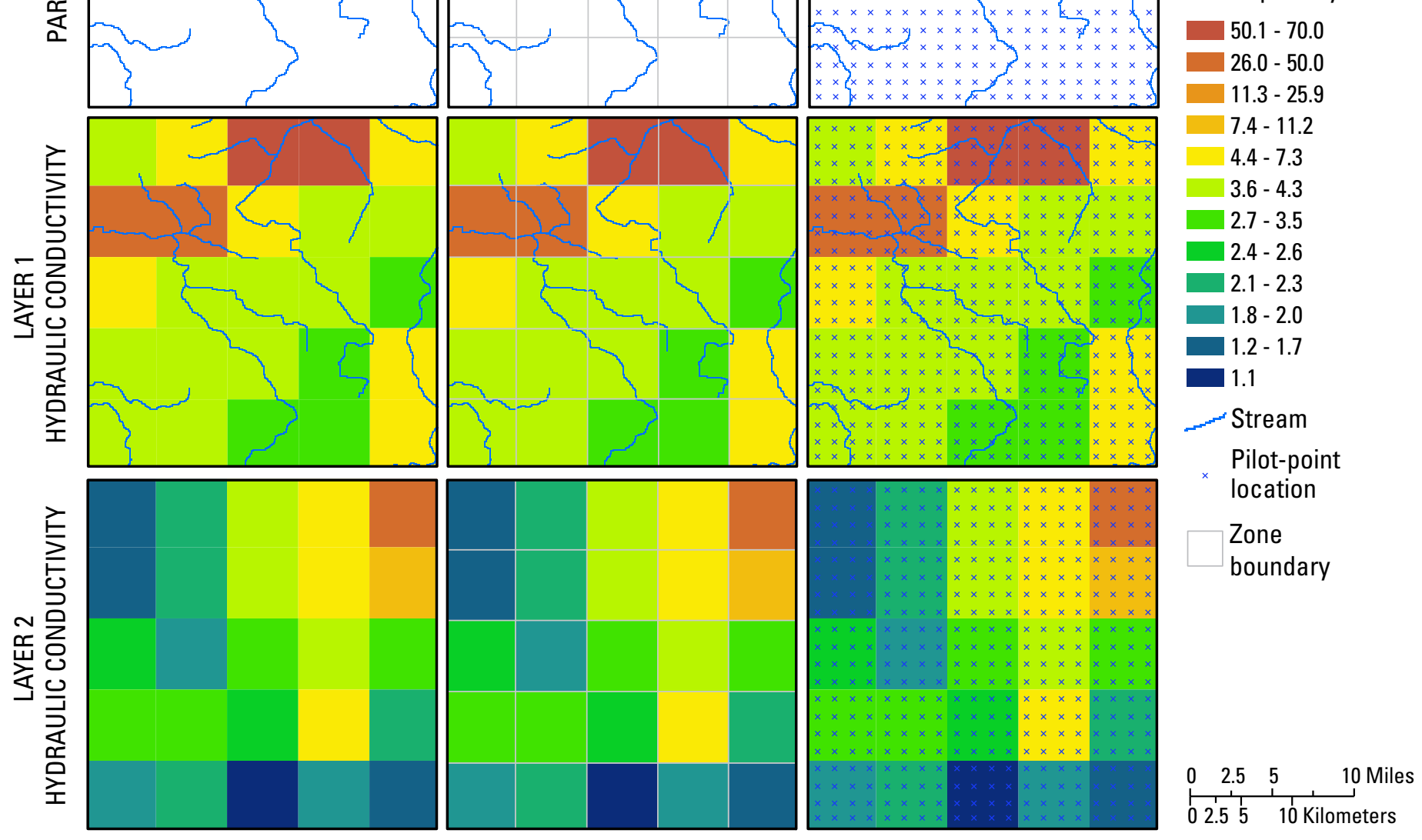

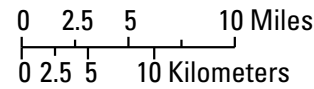

Figure 2. Local model domain showing the parameterization and observation network. The left panel is 1 Zone, the middle panel is 25 Zones, and the right panel is the 400 Pilot Points parameterization. The grid in the 25 Zones panel outlines hydraulic conductivity zone boundaries; the ' $x$ ' marks on the 400 Pilot Points panel show the pilot-point locations.

The degree of parameterization is of interest because it enters the problem in two ways. First, the more zones used to represent the model domain, the smaller the size of each individual zone. Therefore, when each zone is varied independently in the sensitivity analysis, the size of the spatial area of the model domain perturbed is different, which results in different sensitivity results reported in the Jacobian matrix. A second, less obvious, effect is that the resolution of the modeler's expected parameter uncertainty will differ with different spatial parameterization. That is, if a piecewise-constant zone represents the average value of all properties in that zone, a larger zone may have a larger standard deviation around that mean than a smaller zone. Therefore, the 1 Zone case represents the end member of oversimplification as might happen when the model used for assessing data worth is only minimally changed from the regional model conceptualization. That is, in this case, the inset model of Hoard (2010) allowed the surface-water features to be more refined, but the discretization of aquifer properties is not. The 25 Zone case can be considered a more typical case, where the parameter flexibility appropriate for the regional model is assumed to be appropriate for the data-worth calculation, when used in conjunction with the additional surface-water feature refinement of the higher grid resolution of the inset model. This also can be thought of as the number of zones that might be used in a traditional calibration approach. The 400 Pilot Point case represents a highly parameterized approach typical of regularized inversion methods that aim to interject sufficient parameter flexibility such that confounding artifacts associated with model simplification of a complex world are minimized. In this way, the three parameterization approaches can be considered a continuum of degrees of model-parameter flexibility. 
The prediction includes a new stress added to the refined inset model - the addition of one new pumping well, extracting at $500 \mathrm{gal} / \mathrm{min}$ from layer 2 at the location indicated in figure 3 . The prediction, related to the new stress, is the head in a location between the pumping well and stream (fig. 3, cell H115_259 in layer 1) that might represent an area containing groundwater-dependent endangered species. Using PEST, potential head observations were added throughout the model to determine the importance of each possible location for reducing uncertainty associated with a head prediction at cell H115_259, owing to the new stress.

The results of data-worth calculations are contoured and displayed on a map in figure 4. Increasing data worth is indicated by warmer colors, where the values indicate the reduction in prediction uncertainty if the proposed additional data were used in recalibrating the model. These dimensionless values are interpreted relative to one another rather than on an independent scale. The extent of the map is the same as the model domain, and the panels in figure 4 depict results for the first two layers for all three parameterization strategies.
In figure 4 , the differences in the displayed values from the left panel to the right reflect the progressively more flexible parameterization of hydraulic conductivity, from a single-layer multiplier on the left (the simplest, 1 Zone scenario), followed by a 5 by 5 grid of homogeneous zones ( 25 Zones), to a 20 by 20 grid of pilot points (400 Pilot Points) on the right. Two features are evident when comparing the parameterization scenarios: first, counter-intuitive artifacts are encountered in the low (1 Zone) and intermediate (20 Zones) cases of parameter flexibility. The areas reported as most important for reducing the prediction uncertainty of groundwater levels between the well and the headwater stream are counter-intuitive because they are distant from both the stress and the related prediction. Inspection of the locations of the most important data worth indicates that these areas are associated with zone boundaries and intersections - a factor introduced solely by the modeler when the parameter flexibility was specified. When the same data-worth analysis is performed using the highly parameterized (400 Pilot Points) case, locations of higher values of data worth are located where intuition indicates - the area near both the stress and the prediction.

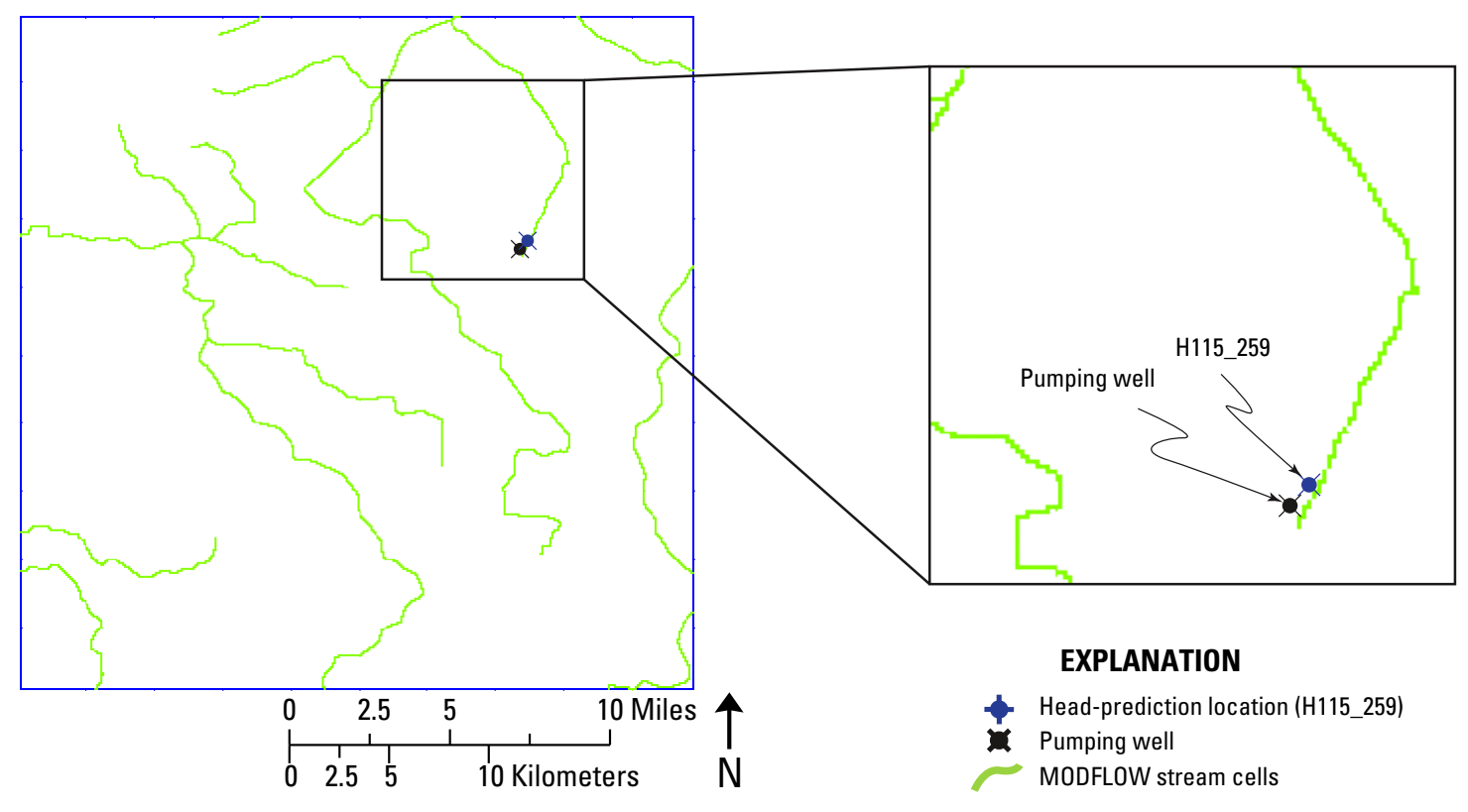

Figure 3. Local model domain and the locations of the pumping well and the head prediction cell (H115_259).

Figure 4. Observation data worth for head-prediction scenario evaluated for layer 1 (upper 3 panels) and layer 2 (lower 3 panels). In each row of panels, three parameterizations are shown: 1 Zone (left panel), 25 Zones (middle panel), and 400 Pilot Points (right panel). Note that the scales vary in each panel to show relative patterns. Details of the units and calculations are in Fienen and others (2010).

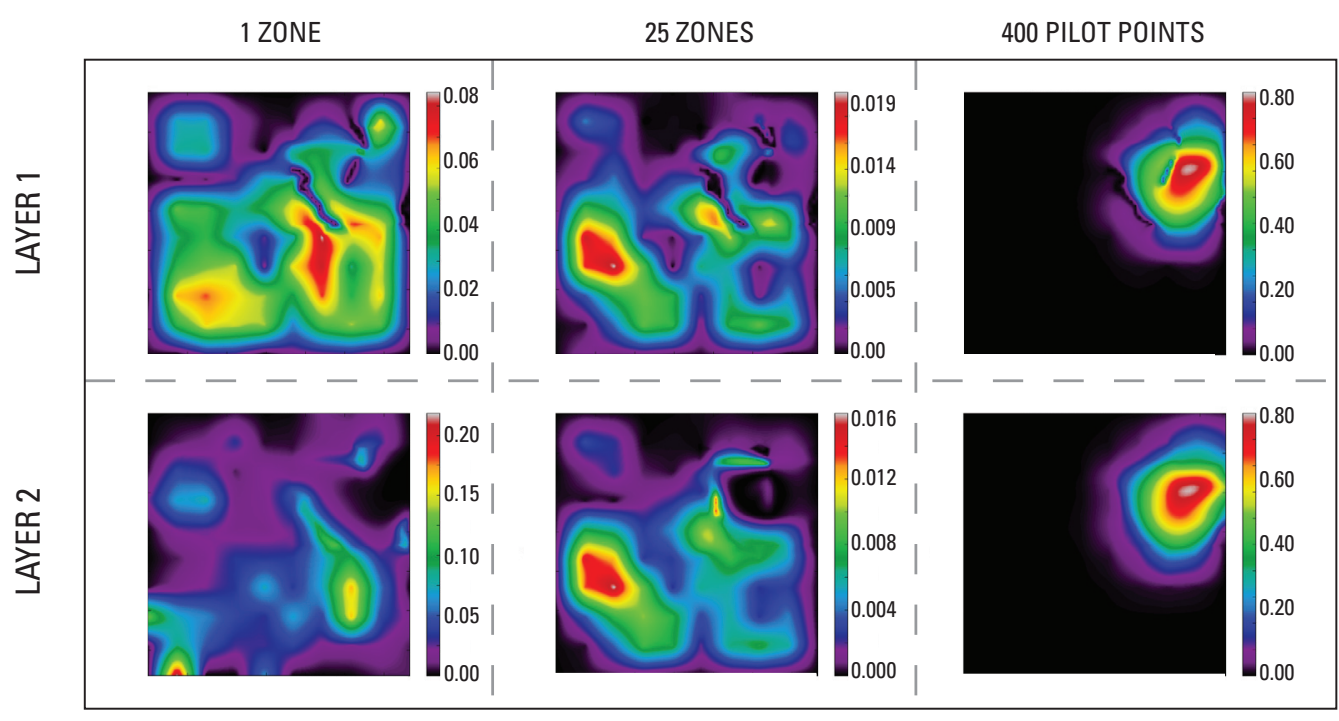




\section{Assessing the Importance of Model Objective for Quantifying Prediction Uncertainty}

Some objectives of a modeling study do not require a great aquifer or system to provide a representative prediction; therefore, this complexity can be excluded from the model. For example, if the objective of a study is one of water balance, such as defining a well's contributing recharge area, this integrates relatively large areas of an aquifer, and the real-world, small-scale distribution of the hydraulic conductivity within that area is less important than the bulk properties. If the modeling objectives are to examine groundwater travel time and location in the groundwater system, these are directly dependent on spatial heterogeneity of hydraulic properties, such as hydraulic conductivity and effective porosity and preferential flow paths. To the extent that oversimplification of the model misrepresents or omits salient details of the system simulated, the predicted location and time of travel will be in error (Moore and Doherty, 2005). Less obvious, perhaps, is the case of a model being parameterized appropriately for one modeling objective, but then used without consideration for a different objective. Such is the concern of using models constructed for an original purpose, then being used in subsequent data-worth analysis. This concern arises because simplifications appropriate for one objective can confound the insights that might otherwise be gained through data-worth analysis. The concern centers on the possibility that outcomes of data-worth analysis in such oversimplified models are more reflective of parametersimplification devices than of the true information content of the hypothetical data collected.

These confounding artifacts of oversimplification are incurred by the sharp (and subjective) regional parameter-zone boundaries in the hydraulic conductivity field specified by the modeler. Oversimplification adversely affects the identification of the optimal potential observation-well location because it can eclipse the ability of the method to discern subtle information within the coarser zone, such as one head location versus an adjacent head location within the same zone. The parameter flexibility afforded the 400 Pilot Point case overcomes the confounding effects of oversimplification caused by the hardwired imposition of hydraulic conductivity piecewise-constant change that occurs at the zonal boundaries. Thus, the resolution of the parameter flexibility required for the model is a direct result of the resolution of the question being asked of the model. In the case of the original pumping-stream depletion waterbalance objective of Hoard (2010), the regional model level of parameterization was appropriate. However, when the model objective changed and became smaller scale (ranking the data worth of one observation well location over a nearby location), a parameter-flexibility level was needed that was commensurate with the spacing of the proposed observation wells, not the regional model calibration targets. Note that it is the parameterization flexibility that is required, not different parameter values specified in the model input (as the actual parameter values were identical in all three cases).

\section{Application for Monitoring-Network Design}

For the highly parameterized 400 Pilot Points case in layer 1, the location of a southwest-northeast trending stream near the stress and prediction can be seen as reducing data worth for potential head observations, as would be expected given the ability of the stream to constrain the sensitivity of nearby heads (Hunt, 2002). There is asymmetry in data worth about the stream, with potential observations east of the river having greater data worth. This is noteworthy because the prediction (and pumping) is on the western side of the stream; however, the greater importance of the eastern part of the domain reflects the ability of this area to constrain the distribution of groundwater flow captured by the stream and that which underflows the stream and is captured at the well. The distribution of underflow and stream capture is more easily seen when not near the pumping stress. The small data worth for potential observation wells located very near the stream itself is a reflection of the dampening effect the stream has on the sensitivity of adjacent potential observation heads. In this case, potential head observations near groundwater divides have more relative worth than potential observations near surface-water features. This is consistent with the results of Hunt (2002) and Sheets and others (2005) and can be considered a general result that likely is transferable to many monitoring-network design problems.

\section{Parameterization Implications from Monitoring- Network Analysis}

Parameterization flexibility must be commensurate with the model objective (Hunt and Zheng, 1999; Hunt and others, 2007). Coarse parameterization flexibility appropriate for a regional or large-scale water-balance objective that integrates large areas of the model domain likely is inappropriate for quantifying the worth of potential observation-well locations. Oversimplification by analytical solutions or overly strict homogeneous, isotropic assumptions can result in poor representations of the response of natural systems (Hunt and Welter, 2010). The role of parameterization in uncertainty analysis, and the significant cost that can accompany simplifying the natural world into models, also is consistent with the findings of Moore and Doherty (2006).

The prediction of interest ultimately defines the data-worth analysis objective, and thus the optimal network design. Different predictions may require different levels of parameterization flexibility; however, starting with a high level of flexibility helps ensure that a model is suitable for a range of objectives, for data-worth analyses of a high-resolution question also will be appropriate for data-worth analyses of a low-resolution question. Moreover, the converse is not true. Thus, true to the highly parameterized approach of Doherty and Hunt (2010a), "if in doubt, include it." That is, the computational savings gained during calculating the sensitivity from an oversimplified model is more than offset by the often unquantified confounding artifacts introduced by oversimplification. As shown here, these artifacts can completely obfuscate any insight gained from a data-worth analysis. 
In summary, broad, piecewise-constant zones may represent prior knowledge about the hydrogeologic conceptualization of a model and may be appropriate for large-scale model predictions (see Haitjema, 1995, p. 272, 274, and 279). A data-worth objective such as comparing the importance of one potential observation-well location to another nearby potential location requires a parameterization scheme that is commensurate for the observation network being tested. Therefore, although existing off-the-shelf models provide a useful quantitative framework to assess data worth of potential data collection, it is unlikely they can be used directly without some additional parameter flexibility, even if the prediction itself can be appropriately simulated using coarse parameter representations. That is, the parameterization should reflect the representative scale of the range of predictions the model is to evaluate, not necessarily the scale of the original prediction of interest.

\section{References Cited}

Beven, K.J., 1993, Prophecy, reality and uncertainty in distributed hydrological modeling: Advances in Water Resources, v. 16 , no. 1, p. $41-51$.

Doherty, J.E., 2003, Ground water model calibration using pilot points and regularization: Ground Water, v. 41, no. 2, p. 170-177, doi:10.1111/j.1745-6584.2003.tb02580.x.

Doherty, J.E., 2010, Addendum to the PEST manual: Brisbane, Australia, Watermark Numerical Computing, 272 p.

Doherty, J.E., and Hunt, R.J., 2010a, Approaches to highly parameterized inversion-A guide to using PEST for groundwater-model calibration: U.S. Geological Survey Scientific Investigations Report 2010-5169, 59 p.

Doherty, J.E., and Hunt, R.J., 2010b, Response to comment on "Two statistics for evaluating parameter identifiability and error reduction": Journal of Hydrology, v. 380, no. 3-4, p. 489-496, doi: 10.1016/j.jhydrol.2009.10.012.

Feinstein, D.T., Hunt, R.J., and Reeves, H.W., 2010, Regional groundwater-flow model of the Lake Michigan Basin in support of Great Lakes Basin water availability and use studies: U.S. Geological Survey Scientific Investigations Report 2010-5109, 379 p.

Fienen, M.N., Doherty, J.E., Hunt, R.J., and Reeves, H.W., 2010, Using prediction uncertainty analysis to design hydrologic monitoring networks - Example applications from the Great Lakes Water Availability Pilot Project: U.S. Geological Survey Scientific Investigations Report 2010-5159, 44 p.

Fienen, M.N., Hunt, R.J., Krabbenhoft, D.P., and Clemo, T., 2009, Obtaining parsimonious hydraulic conductivity fields using head and transport observations - A Bayesian geostatistical parameter estimation approach: Water Resource Research, v. 45, W08405, 23 p., doi:10.1029/2008WR007431.

Haitjema, H.M., 1995, Analytic element modeling of groundwater flow: San Diego, Academic Press, 394 p.
Harbaugh, A.W., 2005, MODFLOW-2005-The U.S. Geological Survey modular ground-water model-The ground-water flow process: U.S. Geological Survey Techniques and Methods, book 6, chap. A16, 256 p.

Hoard, C.J., 2010, Implementation of local grid refinement in MODFLOW for the Lake Michigan Basin regional groundwater flow model: U.S. Geological Survey Scientific Investigations Report 2010-5117, 25 p.

Hunt, R.J., 2002, Evaluating the importance of future data collection sites using parameter estimation and analytic element groundwater flow models, in Proceedings from the XIV International Conference on Computational Methods in Water Resources Conference, Delft, The Netherlands: Elsevier, v. 1, p. 755-762.

Hunt, R.J., Doherty, J.E., and Tonkin, M.J., 2007, Are models too simple? Arguments for increased parameterization: Ground Water, v. 45, no. 3, p. 254-262, doi:10.1111/j.17456584.2007.00316.x.

Hunt, R.J., and Welter, D.E., 2010, Taking account of "unknown unknowns": Editorial for Ground Water, v. 48, no. 4, p. 477, doi: 10.1111/j.1745-6584.2010.00681.x.

Hunt, R.J., and Zheng, Chunmiao, 1999, Debating complexity in modeling: EOS, Transactions, American Geophysical Union, v. 80, no. 3, p. 29.

Moore, C.R., and Doherty, J.E., 2005, Role of the calibration process in reducing model predictive error: Water Resources Research, v. 41, W05050, 14 p., doi:10.1029/2004WR003501.

Moore, C.R., and Doherty, J.E., 2006, The cost of uniqueness in groundwater model calibration: Advances in Water Resources, v. 29, no. 4, p. 605-623.

Sheets, R.A., Dumouchelle, D.H., and Feinstein, D.T., 2005, Ground-water modeling of pumping effects near regional ground-water divides and river/aquifer systems - Results and implications of numerical experiments: U.S. Geological Survey Scientific Investigations Report 2005-5141, 31 p.

\section{Written by Michael N. Fienen, Randall J. Hunt, John E. Doherty, and Howard W. Reeves}

\section{For more information, contact:}

Michael N. Fienen, U.S. Geological Survey, (608)821-3894,mnfienen@usgs.gov

Randall J. Hunt, U.S. Geological Survey, (608) 821-3847,

rjhunt@usgs.gov

John E. Doherty, Watermark Numerical Computing and

Australian National Centre for Groundwater Research and

Training,+61 73379 1664, johndoherty@ozemail.com.au

Howard W. Reeves, U.S. Geological Survey,

(517)887-8914,hwreeves@usgs.gov 